\title{
Why is informed consent important?
}

Decision-making is a prominent theme in this edition of the Journal of Medical Ethics. Our feature article examines the relationship between trust and informed consent. Informed consent is, of course, central to the decision-making process in medicine. In addition, several articles consider decision-making in medicine from a variety of angles.

\section{INFORMED CONSENT AND TRUST: EYAL'S ARGUMENT}

In our feature article, Nir Eyal attacks attempts by bioethicists including Onora O’Neill, Torbjörn Tännsjö, and Jennifer Jackson to ground the importance of informed consent in its role in safeguarding trust in medical practice (see page 437, Editor's choice). The trustpromotion argument for informed consent, as Eyal terms it, states (1) that trust in medical practice is necessary to ensure that people seek and comply with medical advice and participate in medical research, (2) that as a result it is 'usually wrong to jeopardise that trust', (3) that violations of informed consent jeopardise that trust, and (4) that standard informed consent requirements are therefore justified.

Eyal makes explicit that this argument is consequentialist: it takes the value of informed consent to lie in its role in ensuring trust in medical practice; in turn, trust is instrumentally valuable because it promotes health through use of the medical system, compliance with treatment, and participation in research (for brevity, I'll refer to these desirable practices as 'effective use of medicine'). The consequentialist trust-promotion argument, Eyal observes, differs from deontological trust-based arguments, which defend respecting informed consent requirements with reference to factors such as its being an appropriate way of honouring the trust that patients place in doctors.

Eyal attacks the trust-promotion argument on the ground that it does not account for some commonsense intuitions about informed consent. He argues, to cite one of the many problems he raises, that secret breaches of informed consent -for example, treating patients while they sleep-would not undermine trust in medical practice. Another example: he notes that some of the most distrustful patients are those whom it is generally viewed as acceptable sometimes to treat without their informed consent, such as paranoid schizophrenics. If, as the trustpromotion argument alleges, the importance of informed consent is grounded in its capacity to promote trust, then obtaining informed consent from paranoid schizophrenics and other unusually distrustful patients should be more important than it is in normal cases, not less.

Eyal concludes that, despite its initial appeal, the trust-promotion argument fails: the importance of promoting trust in medical practice does not suffice to account for the importance of informed consent.

\section{RESPONSES FROM TÄNNSJÖ AND BOK}

Eyal's article is followed by commentaries from Torbjörn Tännsjö (see page 445) and Sissela Bok (see page 446). Tännsjö, who advances a version of the trust-promotion argument based on hedonistic utilitarianism, denies that the argument runs counter to commonsense views about informed consent. He demonstrates that a hedonistic utilitarian view of informed consent provides the right solutions to the problems Eyal raises. For example, in response to Eyal's argument that defenders of the trust-promotion argument must concede that secret breaches of informed consent are acceptable since they would not undermine trust, Tännsjö argues that utilitarian medical staff would not attempt secret breaches. This is because, in order to be sure of promoting trust, such medical staff must develop 'reliable habits' that involve respecting informed consent requirements. Tännsjö also argues that the utilitarian can account for relaxing informed consent requirements when treating paranoid schizophrenics on the ground that 'they are few, we are many'. This makes it is more important on utilitarian trust-promoting grounds to reassure the many that they would receive appropriate medical treatment were they to become psychotic than it is to reassure psychotic patients that the medical staff attempting to treat them are trustworthy.
Bok, by contrast, agrees with Eyal that there are problems with the trust-promotion argument. She holds that the first premise of the argumentthat trust in medical practice is necessary for ensuring effective use of medicine-is too strong: many patients provide consent despite being, to some extent, distrustful. Bok agrees with the second premise that it is 'usually wrong to jeopardise that trust'. She argues that the reason it is wrong to jeopardise patients' trust in the medical system (and to jeopardise trust in general) is that trust is a prerequisite of cooperation, and hence an important social good. Violating informed consent requirements is wrong, in Bok's view, because it diminishes the 'fragile social resource' of trust, not merely because it reduces effective use of medicine.

Eyal's response (see page 447) focuses mainly on Tännsjö, to whom he sensitively responds that whilst-in the cases discussed by Tännsjö, at least-hedonistic utilitarian considerations give us the right answers to questions about when informed consent should be obtained and respected, they do not go far enough in accounting for commonsense beliefs about informed consent. For example, Eyal argues that, pace Tännsjö, utilitarian principles do not require us to treat psychotic patients without their informed consent in order to promote trust among the 'many' who are not psychotic. Eyal notes that, since the vast majority of people are not psychotic (nor likely to become so) it is implausible to hold that the trust of the non-psychotic is likely to be affected by the way in which the psychotic are treated.

\section{IS INFORMED CONSENT ONLY INSTRUMENTALLY VALUABLE?}

This is an enlightening and important debate, especially since lack of trust in medical research and practice can have worrying consequences, as Eyal and Bok both note. Eyal employs some ingenious and subtle manoeuvres in rejecting the trust-promotion argument, but there is an additional, fundamental problem with the argument that is worthy of mention here.

As noted above, the trust-promotion argument is consequentialist in that it takes informed consent to be valuable 
because it promotes trust, which in turn promotes effective use of medicine. Informed consent, then, is valuable ultimately because it is instrumental in ensuring that people use medicine effectively. This, however, is not a satisfactory account of why informed consent is important in medicine. To see this, consider that other factors could also plausibly be instrumental in ensuring that people use medicine effectively, yet their instrumental value is not sufficient to accord them the sort of central role in medicine that informed consent enjoys. For example, empirical evidence demonstrates that providing patients with financial incentives is an effective way of getting them to use medicine effectively. ${ }^{12}$ If-as advocates of the trust-promotion argument hold-the importance of informed consent consists in its role in getting people to use medicine effectively, then (ceteris paribus) other practices that achieve the same end should be viewed as similarly important. Paying patients to use the medical system is one such practice. We can imagine other promising candidates for such practices, too: providing comfortable seats in surgery waiting rooms, affordable parking facilities, media propaganda to exaggerate the reliability of the medical system, ensuring that medical staff are physically attractive, celebrity endorsements, brainwashing, and so on. I suspect that few would wish to claim that such practices are as central to medicine as informed consent; indeed, some of them are highly undesirable.

As such, informed consent must be important for reasons other than its instrumental value in promoting effective use of medicine, so the trust-promotion argument does not fully account for the importance of informed consent. It would be natural, given this conclusion, to turn to non-consequentialist considerations to explain the importance of informed consent in medicine. For example, a virtue ethics approach could provide insight here: the idea that respecting informed consent requirements is among the virtues we expect our medical staff to cultivate is prima facie appealing.

\section{DECISION-MAKING IN MEDICINE}

A further six articles in the current issue address various other aspects of decisionmaking. Two of these articles relate to groups of patients generally taken to lack decision-making capacity: children and psychiatric patients. Rosalind McDougall and Lauren Notini review cases in the medical ethics literature in which health professionals have overridden parents' wishes about their children's medical treatment, and identify the ethical principles cited in justification of these decisions (see page 448). Rahime Aydin $\mathrm{Er}$ and Mine Sehiralti note the importance and difficulty of making accurate assessments of decision-making competence in psychiatry (see page 453). They compare assessments by medical staff, relatives, and a designated assessment tool, and conclude with some recommendations for improvements in practice.

A further three articles consider decisions about end-of-life care. Yi-Chen $\mathrm{Su}$ outlines some concerns about a recent revision to Taiwanese law that allows physicians to act as sole decision-makers to promote the best interests of incompetent, terminally ill patients in cases where the patient expressed no preferences about end-of-life care while still competent, and where no family members are available to provide surrogate decision-making (see page 484). Su notes that the law provides insufficient guidance about patients' best interests and about what procedures medical staff should follow in such cases. He suggests some procedural safeguards to ensure that the law is ethically implemented. Next, Kenneth Chambaere, Ilse
Loodts, Luc Deliens, and Joachim Cohen survey Belgian decisions to forgo end-of-life artificial nutrition and/or hydration, and find that such decisions generally proceed without discussion with the patient, contrary to existing legislation (see page 501). The authors emphasise the need for medical staff, patients, and their relatives to discuss end-of-life treatment options well in advance of the end of life. In another Belgian survey, Jef Deyaert, Kenneth Chambaere, Joachim Cohen, Marc Roelands, and Luc Deliens note that some end-of-life treatments are potentially lifeshortening, and that it is often vague or otherwise unclear how a given treatment is best conceived (as, for example, euthanasia versus palliative) (see page 505). The authors used a questionnaire to discover how physicians involved in end-of-life care labelled the treatments they administered to their patients, and discovered that whilst the way in which physicians conceive euthanasia is relatively clear cut, their conception of palliative or terminal sedation is more ambiguous.

Finally, Gert Olthuis, Carlo Leget, and Mieke Grypdonck argue that shared decision-making can be burdensome to patients, and that education is needed to help medical staff understand the experience of the patient, and apply this understanding in providing improved care (see page 493).

\section{REFERENCES}

1 Giuffrida A, Torgerson DJ. Should we pay the patient? Review of financial incentives to enhance patient compliance. BMJ 1997;315:703-7.

2 Giles EL, Robalino S, McColl E, et al. The effectiveness of financial incentives for health behaviour change: systematic review and meta-analysis. PLOS ONE 2014;9:e90347. doi:10.1371/journal.pone.0090347

${ }^{\mathrm{i}}$ I am grateful to Kenneth Boyd for some useful feedback 